\title{
Faster, Further and More Sustainable
}

\section{Dear Reader,}

With regard to electric mobility, the opinion expressed recently by the press and the public of VW, Mercedes and BMW in Germany tended to be "too hesitant" or "too lame" and simply "lacking” compared to the unarguably innovative pioneer, Tesla. I am reminded of the 1990s TV series "Dinosaurs" and Baby Sinclair's succinct verbal outbursts: "Not a Tesla" - ergo everyone and everything is stupid. Dieselgate didn't exactly help either; disappointed love makes people holding a grudge.

The picture outside of Germany is different: Shaped sheet metal with German engineering under the hood has so far been subject to lower levels of inflation regarding reputation. And BMW, Mercedes and, in particular, VW are doing a lot to iron out any "not-a-Tesla" dents. The switch concerning electric mobility seems to have been thrown: McKinsey estimates that in 2021 the aforementioned companies will produce more electric vehicles than all Chinese manufacturers together. Thanks to the growing production numbers, the plug could also be gradually pulled on Tesla's business model of selling certificates to the competition (around 1.6 billion US dollars in 2020). The competition, as they say, is gaining momentum.

It may be beneficial for the competition for market leadership to produce a wide range of models with good quality down into the lower price segments. And a further point will be to follow the path to the end with consequence and design and build the vehicles as sustainably as possible. Companies from the sector showed how this can be done with the aid of many smaller projects at this year's Sustainability Award in Automotive 2021; more about this on page 68 . The goal is to use the topic of sustainability as an opportunity to differentiate: To get electric mobility running smoothly will require an overall view of the powertrain technology, total vehicle, and operations and supply chain in combination with a supply of energy that moves toward $\mathrm{CO}_{2}$ neutrality. Otherwise the clean electric car will be no different in (too) many ways to a combustionengine-powered car, just in different places. Whoever manages to get to most environmentally friendly vehicle on the road, from cradle to grave, could then profit from it: beyond the question of whether just (B)EV and whether, or when, the combustion engine will suffer the same fate as the dinosaurs.

Enjoy reading this edition.



Robert Unseld

Responsible Editor

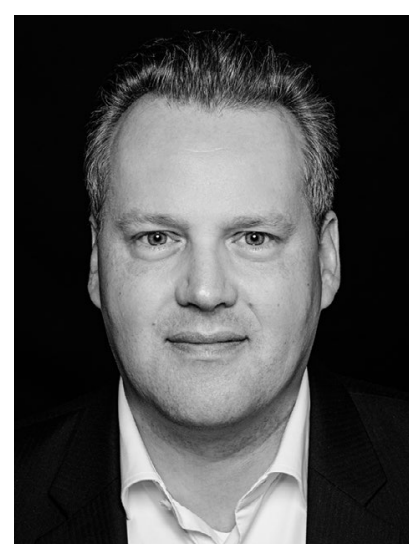

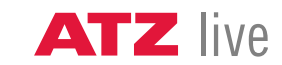

CONFERENCES FOR VEHICLE AND ENGINE SPECIALISTS

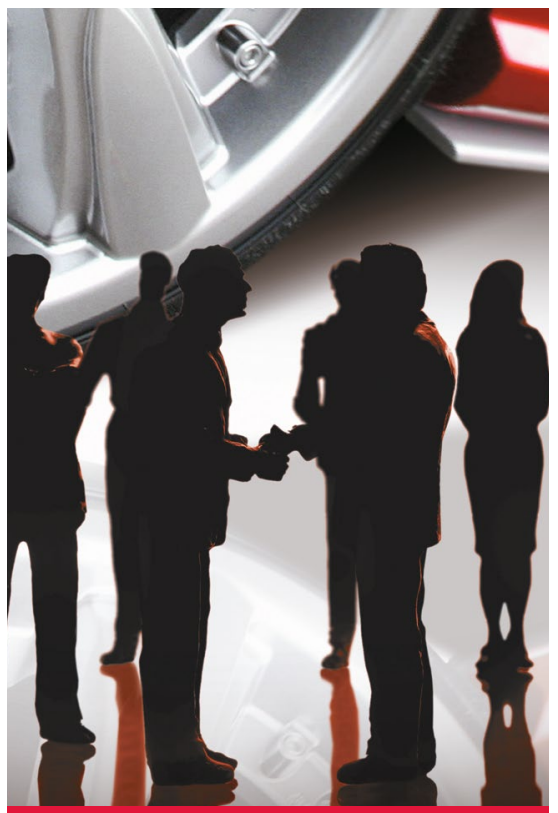

Spotlight on

Powertrain and Vehicle

\section{Engineering}

Forward-looking conferences

I Internal combustion engines and innovative fuels

I Electrified powertrains

I Complete vehicle

I Chassis technologies

Vehicle acoustics

I Mobility and

vehicle concepts

I Autonomous and automated driving

\section{Learn more online now!}

www.atzlive.com 